\title{
Examination of Socio-Economic Support Programs of Small Business Entities
}

\author{
Artur Tuaev ${ }^{1}$, Inara Yagofarova ${ }^{2}$, Irina Chuchkalova ${ }^{2,}$, Oxana Kolotkina $^{2}$ \\ ${ }^{I}$ The South Ossetian State University named after A.A. Tibilov, Tskhinval, Republic of South Ossetia \\ ${ }^{2}$ The Ural State University of Economics, Yekaterinburg, Russia \\ "Corresponding author. Email: irina.hanzhina.9@mail.ru
}

\begin{abstract}
This article is devoted to the examination of state support programs of small business entities in Russia, based on the ratio of the effectiveness of preferential lending and digitalization of the activities of small business entities. The authors conclude that it is necessary to improve state programs in terms of the formulation of specific lending instruments, software, personnel retraining, etc., which can be subjected to economic calculations and, based on the effectiveness of the small business entity, be selective in providing preferences to it.
\end{abstract}

Keywords: examination, state programs, small and medium business entities, support, effectiveness.

\section{INTRODUCTION}

For more than a decade, business activity has been manifesting itself as one of the key components of the developing Russian market. Of course, the active position of the state, which is able to stimulate the development of business with various instruments, is of great importance in this process.

The state's support of small business is especially relevant, since it is most exposed to financial risks. This is due to the fact that small business often does not have stable financing, while small and medium enterprises account for 5.6 million economic entities, jobs for 18 million citizens in Russia. Naturally, the large involvement of citizens in small and medium businesses leads to the fact that about one fifth of the gross domestic product of the Russian Federation, and in many subjects of the Russian Federation, a third or more of the gross regional product are created by such organizations [1].

These figures indicate that the Russian Federation has already formed the necessary regulatory and organizational foundations for state support of small business.

Nevertheless, the abundance of regulatory legal acts regulating the support of small business (for example, according to the RLS "ConsultantPlus", public relations in the field of small business development regulates more than ten thousand regulatory legal acts of various legal force).
It is worth noting that the mechanism of regulation of small business in Russia is implemented within the framework of state socio-economic policy, where support programs of these entities act as an independent link of subordinate regulatory legal acts of executive authorities in Russia, which, of course, are only clarifying and should not contradict the norms of federal laws.

The basic law regulating the principles of providing state support of small business is Federal Law No. 209FL dated 24.07.2007 "On the Development of Small and Medium businesses in the Russian Federation" (hereinafter - Federal Law No. 209), in which support of small business is interpreted as the activities of state authorities, local self-government and the functioning of the infrastructure of support of small business entities aimed at implementing measures that are provided for by small business development programs.

Danakin, N.S., Amin, M.Z., Divichenko, O.I. distinguish the following principles of state support of small business: the systematic principle (hierarchy of support levels; variability of support sources, as well as instrumental types of support and forms), the principle of equal opportunities (for all participants in the businessman-state-consumer process), the principle of balance of targets (the relationship and interdependence of meeting the needs of all stakeholders of societyimplementing entities) [2]. 
The world experience of using state support instruments is reviewed and systematized in the works of scientists from different countries [3-6].

The issues of conducting examinations of state support programs of small business entities, including financial, credit and guarantee aspects, are considered in scientific papers of Zabolotskaya, Victoria V., Pavlenko, S., Lovkova, E., Sheina, E., Kurdyumov, A. [7-9].

Thus, the legislation refers to the norms of subordinate regulatory legal acts, the level of effectiveness of small business support should be assessed as the effectiveness of the implementation of state support programs.

Speaking about the level of subordinate acts, especially it would be desirable to note the orders of the President of the Russian Federation (hereinafter referred to as "the President of the Russian Federation") to the Government of the Russian Federation (hereinafter referred to as "the Government of the Russian Federation"), and in some cases to the All-Russian Public Organization "Russian Union of Industrialists and Businessmen" and the All-Russian Public Organization "Delovaya Rossiya", defining the key areas of strategic development of support programs of small business entities:

- $\quad$ support at the regional level of investment projects implemented by small business entities (Order of the President of the Russian Federation No. 562, item 2 a);

- application of the system of preferential interest rates to small business entities or reduction of the interest rate on loans for small business entities by providing subsidies to reimburse their lost income on loans issued in 2019-2024 from the federal budget (Order of the President of the Russian Federation No. 1726SS, item 7 b);

- digitalization of the activities of small business entities to improve their production and sales activities through the introduction of at least three services that have been developed in subjects of the Russian Federation and their integration among themselves (Order of the President of the Russian Federation No. 1726SS, item 7c).

Despite the fact that from the point of view of the theory of law, subordinate acts do not have such a strict hierarchy as laws, nevertheless, acts of the President of the Russian Federation are an impulse for the activities of the Government of the Russian Federation and have a significant impact on it.

Thus, we see, on the one hand, the expansion of the state's approach to regulating the support of small business in Russia, and on the other hand, the preservation of the task of digitalization of the economy, which also occurs by legal means: mainly small business development programs developed by various executive authorities in Russia.

\section{MATERIALS AND METHODS}

To understand the specifics of legal regulation of support of small business, it is inevitable to conduct a legal examination of the relevant state programs, which is methodologically based on general scientific research methods: analysis, synthesis, deduction and induction, abstraction, structural-functional method and private scientific methods of legal analysis: formal legal, method of legal construction; formal-logical, systematic, technical and legal analysis, a method for determining the economic relations between the level of legal regulation and production indicators. The latter, in turn, should show the influence of the state program on solving common problems of the economy.

\section{RESULTS AND DISCUSSION}

The examination of support of support small business entities should be carried out taking into account the administrative and management activities of the state, which are implemented by various means, among which legal and economic regulation are of fundamental importance, being in close relationship with each other.

Therefore, the effectiveness of the state administration of digitalization of the economy (established by the national strategy and other regulatory acts) will have positive dynamics only with a comprehensive analysis of legislation and specific economic indicators of the enterprise's liquidity, taking into account the phased introduction of digitalization into its activities.

It should be taken into account the existence of legally established restrictions on the provision of state guarantees, which are contained in Federal Law No. 135 FL of 26.07.2006 "On Protection of Competition", where Article 4 states that the state guarantee is a form of state preference - an advantage that provides more favorable conditions for individual business entities. The state guarantee, as a type of preference, may not be provided to all small business entities; otherwise, the guarantee will not be a preference if it is provided equally to each participant in the product market (Part 5 of Article 19 of Law No. 135-FL).

As the part of this research, state support programs of small business entities containing general guarantees for small business ones will be analyzed.

\subsection{Examination of the effectiveness of support programs of small business entities in the field of preferential lending}

The Decree of the Government of the Russian Federation No. 1031 dated June 28, 2021 "On Approval of the Rules for Provision Subsidies from the Federal Budget to the Russian Information Technology 
Development Fund for Reimbursement of Expenses for the Use of Russian software by Small and Medium Business Entities" defines two criteria for receiving an appropriate subsidy from the Fund:

- the average number of employees of a small and medium business entity for the previous calendar year is no more than 250 people;

- the maximum value of income received from the implementation of business activity by a small and medium business entity for the previous calendar year, determined in accordance with the procedure established by the legislation of the Russian Federation on taxes and fees, summed up for all types of activities carried out and applied under all tax regimes, is no more than 2 billion rubles.

The economic calculation of the level of implementation of the program is based on two basic formulas:

The amount of reimbursement of expenses of the support recipient for the $\mathrm{i}$-th type of licenses $\left(3_{\mathrm{i}}\right)$ is determined by the formula:

$$
3_{\mathrm{i}}=\sum_{\mathrm{i}=1}^{\mathrm{n}} \mathrm{Q}_{\mathrm{i}} \times \frac{\mathrm{H}}{2},
$$

where: $\mathrm{Q}_{\mathrm{i}}$ is the number of $\mathrm{i}$-th type licenses provided by the copyright holder (authorized organization) to small business entities at a preferential price; $H$ is the average market price of type i-th type licenses.

The amount of the subsidy provided to the Fund in the corresponding financial year $(\mathrm{C})$ is determined by the formula:

$$
\mathrm{C}=\sum_{\mathrm{i}=1}^{\mathrm{n}} 3_{\mathrm{i}}+\mathrm{O}_{\mathrm{i}} \text {, }
$$

where: $\mathrm{O}_{\mathrm{i}}$ is the amount of expenses to support the Fund's activities related to the achievement of the program target, reimbursement of expenses for the use of Russian software by small business entities.

At the same time, the program target is to reimburse the expenses of using Russian software by small business entities in the analyzed Decree of the Government of the Russian Federation indicates the number of Russian software licenses provided to small and medium business entities at a preferential price.

After the economic calculations have been carried out (calculations are taken for a calendar year), the final values of the result by year (a specific quantitative characteristic of the results) are correlated with the reference values fixed in the passport of the federal project "Digital Technologies" of the national program "Digital Economy of the Russian Federation".
The degree of achievement of the subsidy result is annually assessed by the Ministry of Digital Development, Communications and Mass Communications of the Russian Federation by comparing the actual value of the subsidy result and its planned value.

There are two obvious faults here: the low legal elaboration of the requirements for small business entities that can claim this benefit, and secondly, a certain "formality" of the economic indicators of the quality of the benefits provided: it is obvious that the fact of the functioning of a specialized information resource for a small business entity does not yet indicate its convenience, increased productivity or sales, and the criteria "the number of measures to popularize the acquisition of Russian software by small and medium business entities at a preferential price" also do not indicate real support for business and reduction of their software maintenance expenses.

Moreover, according to paragraph 20 of the Decree of the Government of the Russian Federation No. 1031 of June 28, 2021, the selection of copyright holders authorized to provide software is implemented not by small business entities, but by the Fund itself, which indicates a low degree of consideration of the needs of small business entities.

When analyzing socio-economic support programs of small business entities, it is worth noting the low legal elaboration of a number of them. Thus, the Decree of the Government of the Russian Federation No. 1322 of December 1, 1994 "On measures to ensure the participation of small non-state business in the implementation of state programs and the execution of orders for state needs" does not contain specific measures that should allow small business entities to be more involved in the procedure for the implementation of orders for state needs. The only effective measure in this Decree of the Government of the Russian Federation can be called the requirement to include in the list of information services information about the possibility of participation of small non-state business in the implementation of state programs and execution of orders for state needs, as well as information about small nonstate business, their activities and productions, works (services).

The system-forming act in the field of assessing qualitative and quantitative indicators of the development of the small business support system is the Decree of the Government of the Russian Federation No. 316 dated April 15, 2014 "On Approval of the State Program of the Russian Federation "Economic Development and Innovative Economy".

The quantitative indicators of the Program's implementation are: an increase in the number of employees in the field of small and medium businesses, 
including individual businessmen, to 24.5 million people by 2024; an increase in the position of the Russian Federation in the World Bank's Doing Business rating from 120th place in 2012 to 20th place by 2024; a maintaining the level of satisfaction of citizens of the Russian Federation with the quality of public and municipal services at the level of at least $90 \%$; an increase in the percentage of indicators, data on which are published in the Unified Interdepartmental Information and Statistical System within the time limits established by the Federal Statistical Work Plan, in the total number of indicators, data on which are published in the Unified Interdepartmental Information and Statistical System, from $70 \%$ in 2012 to $96 \%$ in 2024 ; a percentage of enterprises that have achieved an annual 5\% increase in labor productivity at participating enterprises implementing national project activities under federal and regional management during three years of participation in the project will amount to $50 \%$ by 2024 ; an expenses reduction of infrastructure sector organizations regulated by the Federal Antimonopoly Service in 2024 to $90 \%$ compared to 2013 ; a number of citizens of the Russian Federation placed in collective accommodation facilities by 2024 will reach 75.5 million people.

Qualitative indicators of the Program implementation are: an improvement of business conditions in the Russian Federation; a reduction of investment and business risks; a reduction of excessive administrative and other restrictions, duties, unreasonable expenses for business entities and other activities; an expansion of the positions of Russian companies in the global high-tech markets, transformation of high-tech industries and branches of the knowledge economy into a significant factor of economic growth; a creation of an effective regulatory framework in the field of land relations, state cadastral registration of real estate objects and state registration of rights to real estate and transactions with it, geodesy, cartography and spatial data infrastructure of the Russian Federation; a ensuring high quality provision of state and municipal services; an ensuring organizations of the national economy with highly qualified specialists; increasing guarantees of protection of the rights of legal entities and individual businessmen during state control (supervision) and municipal control; an improving the quality of the current system of strategic documents and creating practical mechanisms for their implementation; an ensuring the public administration system with highly qualified and competent specialists in the field of priority areas of professional development of federal state civil servants.

As it is easy to note, indicators of the effectiveness of the implementation of the presented program are of an interdepartmental nature (combining the activities of the Ministry of Economic Development of the Russian Federation, the Ministry of Finance of the Russian Federation, the Federal State Statistics Service, the
Federal Antimonopoly Service, the Federal Agency for Tourism, etc.), which inevitably refers to the content of departmental programs for the development of small business.

Having analyzed the passports, the main content and appendices of all existing departmental programs within the framework of the program "Economic Development and Innovative Economy", only the expected direct results (short description) of the programs are identified; the main directions of implementation; the relationship with the indicators of the general Program "Economic Development and Innovative Economy", which cannot be considered sufficient, since a real increase in support of small business entities is possible only by determining the instruments that various ministries and departments will use to achieve this target. At the same time, neither the passport nor the appendices contain the programtargeted instruments of the subprogram, despite the fact that these are the actual ways and means of supporting small business entities established in the department. Only two programs (their main part) managed to find specific instruments to support business (see Table 1).

Based on the examination of program-targeted instruments of support programs of small business entities in Russia, it allows us to state the absence of real effective instruments at the level of subprograms according to the program passports, and only two programs "Investment environment" and "Management personnel" contain specific instruments prescribed in the main part of the programs.

This analysis leads to disappointing conclusions that the abundance of programs (target programs have been developed by departments as many as 12 pieces), contain generalized formulations and do not allow identifying specific financial and legal instruments to support small business.

\subsection{Examination of the Effectiveness of Support Programs of Small Business Entities in the Field of Digitalization}

The adoption of fundamentally new laws and subordinate acts that ensure not only the regulation of the digital economy, but also the transition to digital civil circulation of goods and services. In Russia, legal conditions have already been created for the formation of a unified digital environment of trust, in particular: the status of certification centers has been unified; common requirements for a universal (unified) enhanced qualified digital signature have been fixed; opportunities and methods of automated centralized identification of participants in digital relations have been expanded; the status and procedure of civil turnover of digital financial assets have been legalized (first of all, Federal Law No. 259-FL of 31.07.2020 "On Digital Financial Assets, Digital Currency and on Amendments to Certain 
Legislative Acts of the Russian Federation", which comes into force on January 1, 2021).

At the same time, to expand the practice of using electronic civil turnover, the legislator should: determine which written transactions are permissible to make in electronic form; formalize and unify the storage of electronic documents, including fixing the algorithm for creating, storing and using electronic images of paper documents. It is also supposed to stimulate VAT payers providing IT services.

From the examination of subordinate acts of executive authorities, it can be concluded that substantial material expenses are required, covered primarily by the state budget or targeted investments. This is probably why the vast majority of events are still being planned.

Among the already implemented programs aimed at the development of small business, it can be noted: the creation of a public network platform for the management of intellectual property rights and means of individualization; the development, commissioning and operation of GIS "Federal Spatial Data Portal", which provides the availability of information contained in the federal spatial data fund, and GIS "Unified Electronic Cartographic Framework" (while its use by authorities should increase from $13.9 \%$ in 2019 to $100 \%$ in 2024); the conditions have been established and the sources of financing have been found for the project of a domestic Global Multifunctional Infocommunication Satellite System (GMISS); the new services have been introduced in terms of "artificial intelligence" and "robotization" technologies in the FSIS USRRE, etc. Also, the completion of a large number of scientifically based and economically calculated plans and concepts for building a digital infrastructure.

The issues of digitalization are particularly acute for small business entities located in small municipalities. For the development of their activities, it is necessary to fully provide the access to the Internet in all settlements with a population of 250 or more (a total of 13958 small settlements are planned to be provided with wireless Internet by 2024); the creation of secure unified channels of audiovisual interaction of business structures with officials; the creation and promotion of the development of the state segment of the Internet (RSNet network); the introduction of a control system for the provision of communication services in socially significant facilities; the transition to the use of 5G/IMT-20 technology in data transmission (for this, even a separate Concept for the creation and development of 5G/IMT-2020 networks in the Russian Federation has been adopted, approved by order of the Ministry of Communications of the Russian Federation dated 27.12.2019 N 923); by 2024, the creation of a system of data acquisition and processing centers dispersed throughout Russia and resistant to disasters (which should be created on the basis of domestic equipment); the creation of a domestic web platform "Digital Earth", providing collection, processing, storage and use of remote space sensing data of the Earth by 2022; the formation of a Smart City ecosystem, including the Smart City Solution Bank resource and IQ assessment for cities and digitalization of urban economy based on it by 2024; the support for projects of small enterprises developing and implementing digital platforms and technologies aimed at developing information infrastructure (although only 35 projects in 2020 and 50 in 2021); the creation and introduction into industrial operation by the end of 2021 of an early warning system for computer attacks of the Russian telecommunications infrastructure.

Thus, the digitalization of small business will inevitably entail greater automation of processes and a reduction in the number of jobs, which actualizes the issues of unemployment, puts to the state the expansion of opportunities for self-employment and business activity. It is no coincidence that one of the key targets for achieving the national development targets of Russia is pointed as "an increase in the number of individual businessmen and self-employed, up to 25 million people" (paragraph 6 of the "g" clause 2 Decree of the President of the Russian Federation dated 21.07.2020 N 474 "On national development targets of the Russian Federation for the period up to $2030 "$ ".

Russia has already implemented a set of measures to analyze global trends in the development of information technologies in the field of information security of small business; an assessment of potential vulnerabilities, threats and risks of information security has been carried out (primarily when using cloud, fog, quantum technologies, artificial intelligence and augmented reality systems; stability, risks and threats to the safe functioning of a unified telecommunication network, as well as elements of the Russian segment of the Internet. In Russia, priorities for the development of domestic software have been identified, including issues of its compatibility, and requirements for its preferential use are being actively implemented. 
Table 1. Program-targeted instruments of support programs of small business entities.

\begin{tabular}{|c|c|c|}
\hline № & Name of the Program & 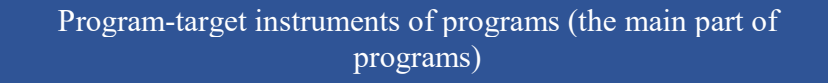 \\
\hline 1 & investment environment & $\begin{array}{l}\text { provision of financial support in the form of grants; } \\
\text { Russian Federation; } \\
\text { competition development of competition in the subject of the } \\
\text { increase of investment attractiveness of territories; } \\
\text { platform that provides practical training in the principles and } \\
\text { instruments of lean production. }\end{array}$ \\
\hline 2 & Development of small and medium businesses & - \\
\hline 3 & State registration of rights, cadastre and cartography & - \\
\hline 4 & Improvement of the public management system & - \\
\hline 5 & Stimulating innovation & - \\
\hline 6 & $\begin{array}{c}\text { Development of antimonopoly and tariff regulation, } \\
\text { competition and increasing the effectiveness of } \\
\text { antimonopoly control }\end{array}$ & - \\
\hline 7 & Management personnel & - improving the management qualifications of business leaders \\
\hline 8 & Improving the system of state strategic management & - \\
\hline 9 & Official statistics & - \\
\hline 10 & $\begin{array}{c}\text { Creation and development of the SKOLKOVO } \\
\text { Innovation Center }\end{array}$ & - \\
\hline 11 & Energy saving and improving energy efficiency & - \\
\hline 12 & Tourism & - \\
\hline
\end{tabular}

\section{CONCLUSION}

An examination of state support programs of small business entities allows us to draw a number of key conclusions about the current state and trends in the development of this sphere of public relations.

Firstly, the interdepartmental nature of support of small business, which, on the one hand, allows regulating these issues from the perspective of the budget system, the educational system, antimonopoly regulation, tourism, etc., nevertheless, makes the procedural aspects of regulation more confusing, forcing us to turn to an overloaded array of subordinate acts.

Secondly, the active role of the state in the process of supporting small business should not develop into total control over business. It is necessary to reduce the general rules and requirements, since state support should be of a stimulating selective nature due to limited budgetary resources. It makes sense to stimulate the most promising economic entities whose activities are the most effective and meet the targets of the socio-economic policy of the municipality.

Thirdly, despite the presence of a significant number of existing indicators in state programs that characterize the state and development of small business, a comprehensive system of indicators suitable for program management targets has not been developed. There are also difficulties in developing a comprehensive system of indicators characterizing the efficiency and effectiveness of state support for the development of small business, which would meet the requirements of objectivity, accountability and modern assessment principles.

Without defining proper (and economically verified) criteria for assessment of the activities of small business, it is difficult to determine the necessary assistance to enterprises that demonstrate the greatest socio-economic effects.

The current Russian legislative acts stipulate the need to calculate the effectiveness of all measures implemented in small business development programs at different levels of state power; however, unified systematized efficiency criteria are not given.

Fourth, the analysis of regulatory acts (first of all, Decrees of the President of the Russian Federation, Decrees of the Government of the Russian Federation, Orders of the Ministry of Finance, the following directions of digital transformation of small business in Russia can be distinguished: the improvement (creation) of regulatory regulation of the digital environment; the creation of the information infrastructure of the economy; the training of personnel for the digital economy; the providng information security; the introduction of digital technologies, including in the field of public administration. At the end of 2019, the federal Artificial Intelligence project was added to these areas (Decree of 
the President of the Russian Federation No. 490 dated 10.10.2019 "On the development of artificial intelligence in the Russian Federation").

\section{ACKNOWLEDGMENTS}

The reported study was funded by RFBR and MES RSO, project number 21-510-07003 «Formation of a financial and investment mechanism for supporting small businesses in the conditions of the formation of a young state.

\section{REFERENCES}

[1] Report of the Federal Antimonopoly Service of the Russian Federation for 2020 "State of competition in the Russian Federation for 2020." https://fas.gov.ru

[2] N. S. Danakin, M. Z. Amin, O. I. Divichenko, State Support Principles for Small Business. Journal of Fundamental and Applied Sciences 8 (2016) pp. 1879 - 1890. DOI: https://doi.org/10.4314/jfas.v8i3s .322 .

[3] V. F. Savchenko, M. G. Dolgopolov, Business Incubators as an Instrument of State Support of Small Business. Scientific Bulletin of Polissia 4 (2016) pp. 202-207.

[4] I. Leibus, V. Verulidze, J. Maksimenko, Simplified Taxes to Support Small Business. New Challenges in Economic and Business Development - 2020: Economic Inequality and Well-Being, 2020 pp. 205214.

[5] S. Burgess, D. Schauder, Small business web site implementation decisions: A decision support tool for small businesses. Issues and Trends of Information Technology Management in Contemporary Organizations 1(2) (2002) pp. 98-101.

[6] K. Mole, Street-level technocracy in UK small business support: Business Links, personal business advisers, and the Small Business Service. Environment and Planning C-Government and Policy 20(2) (2002) pp. 179-194. DOI: https://doi.org/10.1068/c0112.

[7] V. V. Zabolotskaya, Governmental Programs of Small Business Support in the USA. World Economy and International Relations 63(12) (2019) pp. 15-22. DOI: https://doi.org/10.20542/01312227-2019-63-12-15-22.

[8] S. Pavlenko, E. Lovkova, Government Support of Small Business and its Development Mechanism. Strategica: Challenging the Status Quo in Management and Economics, 2018 pp. 46-52.

[9] E. Sheina, A. Kurdyumov, M. Zavyalova, Environmental investment as a factor of sustainable economic development in the context of transformation of the external and internal environment, In: E3S Web of Conferences, 2021, p. 04016 . 